\title{
Multi-function e-scarecrow (MFeSC)
}

\author{
Algaziya Abdullah Alneimi \\ Munnira Jamil Alsaidi \\ Dr. Mohammed Fadlalla Elahag
}

\author{
College of Applied Science - Suhar \\ College of Applied Science - Suhar \\ College of Applied Science - Suhar
}

\begin{abstract}
Humans have taken the (scarecrow) as a protector for these crops from the birds. There are various different types and designs for the scarecrows around the world. In this project we will develop the traditional scarecrows to become electronic and do more than one function at the same time (Multi-functions mechanism). The (MFESC) consists of several components, the most important of them is the sensor, which performs many functions, including sensing the presence of birds' sounds, as well as indicator for measuring temperature and humidity around agricultural crops. Moreover, it will collect some statistical information about the number of birds by using digital camera and other important issues. The (MFESC) provides the collected information to a special information system that connects to it. There are also two arms in this scarecrow and each arm contains some pieces of cloth to move when the device senses the presence of birds. It also produces sound and light to keep birds away and scare them. There will be many electronic scarecrows around the crop, one of which will serve as the main scarecrow. Any place where bird's scarecrow movement and sound and light also send a signal to the main scarecrow predicted the existence of birds issuing a signal to the rest of the scarecrows to issue movement, sound and light. The main scarecrow collects and sends information to the farm's system associated with the (MFESC). As mentioned earlier, an electronic scarecrow will be designed to perform Multi-functions such as keeping birds away, collecting birds' statistical information as well as collecting information that related to humidity, temperature, and more over it detects the smoke as an indicator for fire problem. For that reasons we will replace traditional scarecrow by electronic one.
\end{abstract}

\section{Introduction}

At first we can say that the agricultural field began to spread since the beginning of life on this land. Agriculture is the most important component of life on earth. It is one of the main sources through which people get food and keep it alive, and are widespread in some areas around the world. It can be considered as a craft or art of the art followed by man in his life, which leads to access to agricultural crops that he needs and the right amount as well. There are a number of uses that agriculture provides to humans in their daily lives, including:

1. Abundant human needs for food, housing and clothing, which are among the most important necessities in human life.

2. Agriculture works to provide a lot of essential and essential industries in life, such as medical resources and others.

In addition, there are many types of agriculture around the world and the most important types are:

1. Traditional or developing agriculture: old agricultural machinery and tools are used in the agriculture process. This type does not cover the large needs of people food.

2. Advanced agriculture: It is in the use of modern agricultural tools.

It is worth mentioning that over time, the agricultural field in some countries is threatening to disappear for a number of reasons, so the farmer is trying to protect his farm by many means and therefore to reduce those risks caused by man and animal together. It is also known that humananimal (especially bird) relationship is beautiful, except when competing for food. To solve this 


\section{Journal of Student Research}

Fourth Middle East College Student Research Conference, Muscat, Sultanate of Oman

problem the idea of scarecrow came, which has spread widely from time immemorial, the invention created by man to keep migratory birds and researchers looking for food. It is said that scarecrow is not a new one but is found from ancient times. Pharaohs are the first to use scarecrow. The first scarecrow mentioned in history appeared in the Nile Valley, where farms were put it, in order to frighten some species of birds. They were installing a piece of wood hanging on it a set of nets to which birds come and located inside. After that, the idea of scarecrows began to develop in many countries around the world until it reached Arab countries, including Oman. It is known that the Sultanate abound agricultural environment and has many different farms. In addition, many farmers use scarecrows to keep their crops from being ruined by birds and other animals.

It is necessary to mention that there is no specific form of scarecrow but its form depends on the way the scarecrow is made. The result of deformation in everybody is horror, the main function for which scarecrow came. It is often a statue or a form made of wood. The farmer dressed many clothes to appear in the form of human beings, including those who painted and decorated in many ways. It is also known that scarecrow is rife in the Sultanate of Oman because of the increasing interest of farms in the farm. Through our field visits to many Omani farms, we noticed that farmers are making scarecrows and dressed in traditional Omani clothes to look like frightening human body.

Because of that we live in rural areas where many farms, also through what we have seen in our lives that related to this topic we decided to work in this project to facilitate the life of the farmer and enable him to monitor his farm without the presence of it. The idea of the project is to convert the traditional scarecrow into an electronic scarecrow that does many function. we will transform the traditional scarecrow into an electronic scarecrow with multiple functions. This electronic scarecrow uses some electronic tools such as sensor also there is a special system to send scarecrow information. There are some goals that have encouraged us to transform traditional scarecrow into electronic:

- Developing expertise in the field of Internet of things and artificial intelligence.

- Electronic scarecrow has multiple functions and not just dimensions of birds.

- Implement something new that serves the community.

- Collect data on the farm helps in finding solutions.

- Protect crops more effectively.

- Calculate the humidity and temperature performed by the sensor in electronic scarecrow.

\section{Section 1 (Technical feasibility):}

In our project, we will need many tools to complete the project well like many kinds of sensors, Digital camera, a measure of temperature and humidity, router, cables, particularly sensor for smoke, internet access, computer and other tools.

To collect a lot of information about the project we have made many field visits, and we gathered some information about the traditional scarecrow of farmers.

- Farmers say that the traditional scarecrows they use in the fields are a structure or body that resembles the human body made from many simple tools that are used for specific purposes. The idea of using scarecrows is an old one inherited by farmers from their former parents. 


\section{Journal of Student Research}

- Traditional scarecrow ingredients:

- Farmers say the traditional scarecrow is a simple model made of simple tools that include a piece of wood used longitudinally to help the scarecrow to stand, as well as two pieces of wood used as arms. The farmer dressed in this form traditional clothes or any kind of colored pieces. In some cases, some farmers form the head of this model in a terrifying form.

- As for how the scarecrow works, it is very simple once the scarecrow is designed to begin its work, which is basically protecting the farm from birds and other animals.

- The idea of scarecrow work came through its inheritance by parents and grandparents. This idea of action is as old as history.

\section{Section 2 (Literature Review):}

We have made many attempts to search for similar projects implemented in reality, and we have found some of the ideas or projects that contain some of the ideas that we put forward in our project but does not contain the idea of our work in an integrated way, such projects: Agrilaser Autonomic: It is an automatic technique that expels animals, especially birds from agricultural areas from a distance of 12 square kilometers. Once the laser light is close to the bird, it automatically moves away. In addition, the presence of a laser light that works throughout the day keeps birds out of place. This device is environmentally friendly

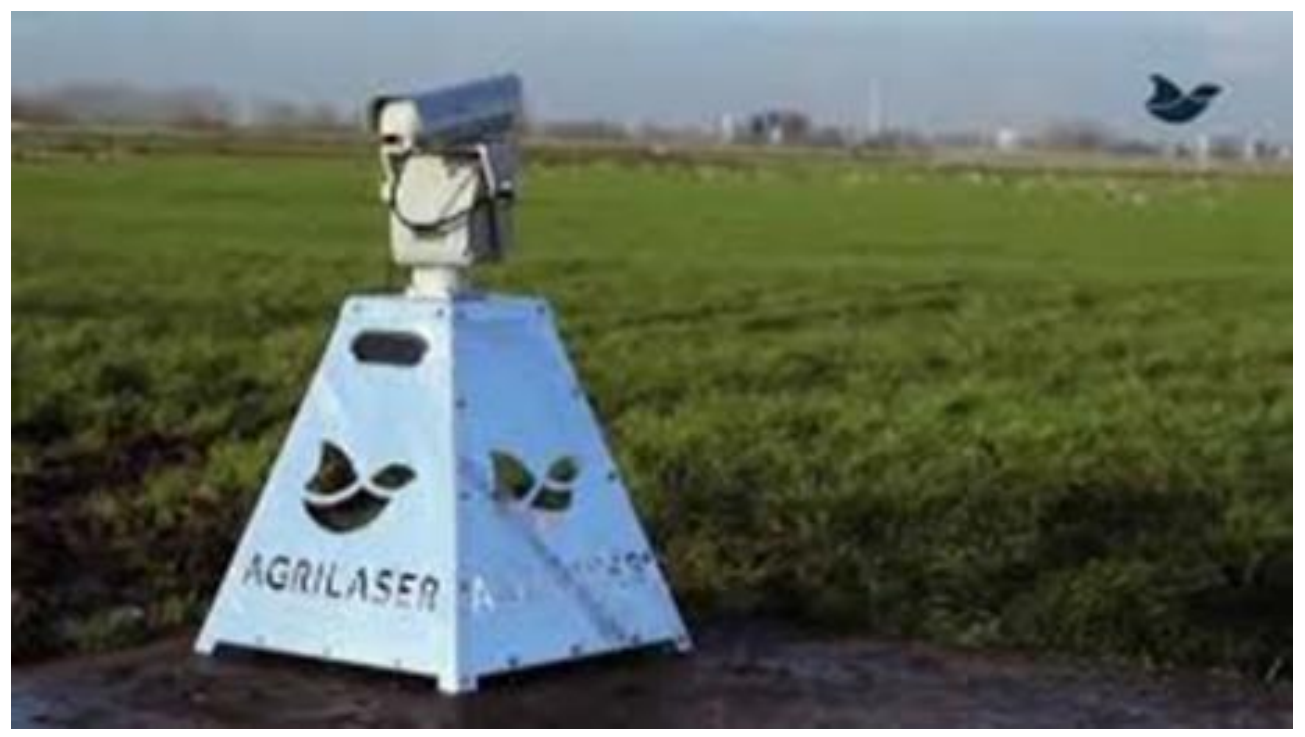

Figure 1.

\section{Experimental Procedures (Cost of the real project):}

We can say that the initial cost that will be determined for the project (MFESC) is about 3500 RO. In addition, the cost that will be allocated to the project is somewhat not appropriate compared to the traditional scarecrow, which is currently designed by farmers, which is very cheap does not exceed 5 RO.

\begin{tabular}{|l|l|}
\hline Component & Cost \\
\hline Piece of wood Cloth Colors & 2RO 2RO 0.5RO \\
\hline Total & $5 \mathrm{RO}$ \\
\hline & \\
\hline
\end{tabular}


Table 1.

The way that the traditional scarecrow is carried out is a basic example of protecting the farm from animals (They form a terrifying body for birds or other animals and thus move away from the field). We will develop this scarecrow using many equipment and we will try to be as useful to the farmer as possible and can dispense with the traditional scarecrow with its existence. Moreover, we conduct study for trying to estimate the cost of the proposed e-scarecrows:

\begin{tabular}{|l|l|l|}
\hline Components & Item Type & Cost(RO) \\
\hline $\begin{array}{l}\cdot \text { Many type of sensors(Light, sound, } \\
\text { movement) }\end{array}$ & Hardware & $10 \mathrm{RO}$ \\
\hline$\cdot$ Mobile device & Hardware & $60 \mathrm{RO}$ \\
\hline$\cdot$ Computer & Hardware & $140 \mathrm{RO}$ \\
\hline$\cdot$ Digital Camera & Hardware & $35 \mathrm{RO}$ \\
\hline$\cdot$ Cable & Hardware & $20 \mathrm{RO}$ \\
\hline$\cdot$ Router & Hardware & $20 \mathrm{RO}$ \\
\hline$\cdot$ Internet Access & Hardware & Free \\
\hline$\cdot$ A measure of temperature and \\
humidity & Hardware & $50 \mathrm{RO}$ \\
\hline$\cdot$ Particularly sensor for smoke & Hardware & $10 \mathrm{RO}$ \\
\hline$\cdot$ Java & Hardware & Free \\
\hline$\cdot$ Mobile Application & Software & Free \\
\hline$\cdot$ My SQL & Software & Free \\
\hline & Software & Free \\
\hline Total & - & 345 \\
\hline
\end{tabular}

Table 2.

\section{Results}

\section{Advantages of the new system:}

For any new system or any new project there are many advantages and benefits that are the reason behind the establishment of it (the goal of the project), which can emerge if the work is implemented in an integrated manner. The idea of our project is a new idea and combines a lot of previous and new ideas into a single technical work that can be used in many areas such as farm protection, also can be used in factories because some of the characteristics it contain, such as extinguishing fires.

\section{Discussion}

Here are some of the benefits of the device that we are going to implement it, such as:

- Measuring the temperature and humidity of the atmosphere:

The device will be able to measure the temperature and humidity of the atmosphere surrounding the crop in order to protect crops from their impact. It is known that there are some crops that do not adapt to the high temperatures that characterize the atmosphere of the Sultanate and thus is the reason behind the death of the crop so, thus lead to a large financial loss for the farms. The device will be set to a certain temperature and humidity and when the temperature or humidity exceeds that degree, some sensors in the device will alert the farmer to take some preventive measures. 


\section{Journal of Student Research}

Fourth Middle East College Student Research Conference, Muscat, Sultanate of Oman

- The property of keeping birds and other animals from around crops:

This device contains three types of sensors (motion sensor, light sensor, and sound sensor). For example, at night, the light sensor should work because it is most effective with night darkness. In the daytime, the motion sensor can work when the birds are too close to the crop, or it can also act as a sound sensor, which will produce an annoying sound that is hostile to these animals.

- Fire extinguishing property:

In fact, there are many fires that can occur on farms for many reasons, including deliberate, accidentally or naturally. The device that we will implement will extinguish the fire if it exists in the case of the presence of the farmer or in his absence also because it depends on a special sensor for the smoke, while he felt the presence of smoke on the farm will pump water on the farm.

- Keeping the farm safe:

The device acts as a guard for the farm as it will be present in the farm all day.

- Gathering statistical information:

With the camera in the device we can get statistical information about the people approaching the farm and also the animals that pass through it.

\section{Conclusion}

In the end we can say that the electronic scarecrow that we will implement will make it easier for the farmer a lot of time and effort as well. In addition, they can be used in factories because of the fire extinguishing property in them, it is known that the factories are an environment in which fires occur largely because of their use of machines and others. If the device is implemented ('MFeSC) it will be of scientific and economic value.

\section{Acknowledgements}

We want to thank Dr. Mohammed Fadlallah for his help in completing this project and to guide us step by step. We would also like to thank Mr. Khalid Al Busaidi, owner of the transistor store, who gave us some tips on the tools we will need during the implementation of the project and how to use them. Our thanks are also extended to the professors of the engineering department of the faculty and our families for their full support.References

Di Laurenzio, L., Wysocka-Diller, J., Malamy, J. E., Pysh, L., Helariutta, Y., Freshour, G., ... \& Benfey, P. N. (1996). The SCARECROW gene regulates an asymmetric cell division that is essential for generating the radial organization of the Arabidopsis root. Cell, 86(3), 423-433.

Kamp, Jon (29 November 2013). "New Scarecrows for Vineyards: Car Dealers' Inflatable 'Dancing' Tube Men". Archived from the original on 2013-11-29 - via Wall Street Journal.

"Kettlewell Scarecrow Festival draws in crowds". Bbc.co.uk. 2011-08-14. Retrieved 2012-07-12.

Heo, J. O., Chang, K. S., Kim, I. A., Lee, M. H., Lee, S. A., Song, S. K., ... \& Lim, J. (2011). Funneling of gibberellin signaling by the GRAS transcription regulator scarecrow-like 3 in the Arabidopsis root. Proceedings of the National Academy of Sciences, 108(5), 2166-2171.

Slewinski, T. L., Anderson, A. A., Zhang, C., \& Turgeon, R. (2012). Scarecrow plays a role in establishing Kranz anatomy in maize leaves. Plant and Cell Physiology, 53(12), 2030-2037. 
Lim, J., Helariutta, Y., Specht, C. D., Jung, J., Sims, L., Bruce, W. B., ... \& Benfey, P. N. (2000). Molecular analysis of the SCARECROW gene in maize reveals a common basis for radial patterning in diverse meristems. The Plant Cell, 12(8), 1307-1318.

Spady, W. (2001). Beyond Counterfeit Reforms: Forging an Authentic Future for All Learners. A Scarecrow Education Book. Scarecrow Press, Inc., 15200 NBN Way, PO Box 191, Blue Ridge Summit, PA 17214 (paper: ISBN-0-8108-4009-X, \$19.95; cloth: ISBN-0-8108-4008-1, \$49.95). 